\title{
Correction to: Organizational and Individual Reality of Innovation: Similarities and Differences
}

\author{
Shashwat Shukla, Shantam Shukla, and Sonam Chawla
}

\section{Correction to:}

Chapter 14 in: A. McMurray et al. (eds.), The Palgrave Handbook of Workplace Innovation, https://doi.org/10.1007/978-3-030-59916-4_14

The chapter 14 was inadvertently published with an incorrect affiliation for the chapter Authors. The affiliations have now been corrected in the revised files as follows,

S. Shukla $(\bowtie)$

University of Allahabad, Allahabad, Uttar Pradesh, India

S. Shukla

Indian Institute of Management, Ahmedabad, Gujarat, India e-mail:shantams@iima.ac.in

Also, the affiliation of Adela McMurray has now been corrected on the back cover. 